\title{
Incidence and Risk Factors for Retinopathy of
}

\section{Prematurity (ROP) in Biggest Neonatal Intensive Care Unit in Itay Elbaroud City, Behera Province, Egypt}

\section{Raouf Gaber (D) \\ Osama A Sorour \\ Amr F Sharaf \\ Hisham A Saad}

Department of Ophthalmology, Tanta University, Tanta, Gharbeya Province, Egypt
Correspondence: Raouf Gaber Tanta University Eye Hospital, The Faculty of Medicine, El-Gash St. Medical Campus, Tanta, Gharbeya Province, 31527, Egypt Email Raouf.a.gaber@gmail.com
Aim of the Work: To evaluate the incidence and risk factors for development of retinopathy of prematurity (ROP) in the biggest neonatal intensive care unit (NICU) in Itay Elbaroud City, Behera province, Egypt.

Methods: We studied data of 240 newly born infants with gestational age (GA) $\leq 34$ weeks or birth weight $(\mathrm{BW}) \leq 2000 \mathrm{~g}$ or infants with unstable course who were admitted to the biggest NICU in Itay Elbaroud City, Behera province, Egypt,

between October 1, 2018 and October 31, 2020. There is no standard screening system in Egypt. Furthermore, we had screened babies more than $1500 \mathrm{~g}$, more than 32 weeks and found signs of ROP, so we decided to expand our inclusion criteria to include babies up to $2000 \mathrm{~g}$ of birth weight and up to 34 weeks gestational age in addition to older and heavier babies with unstable course in NICUs. Clinical information about perinatal neonates was collected by reviewing medical charts. The main outcomes are the incidence and severity of ROP. The relationship of clinical risk factors and the development of ROP were analyzed.

Results: The overall incidence of ROP was $34.1 \%$, and the overall incidence of type 1 ROP was $26.3 \%$ of infants. ROP was significantly associated with GA (odds ratio; OR: 6.8; (3.7-12.3), BW (OR: 4.1; 2.3-7.3), apnea, supplementary oxygen administration, and thrombocytopenia.

Conclusion: The incidence of ROP is high in Itay Elbaroud city, Behera Province, Egypt. Immaturity, low birth weight, low gestational age, oxygen administration, apnea, thrombocytopenia, and jaundice are important risk factors for development of ROP.

Keywords: birth weight, gestational age, incidence, retinopathy of prematurity

\section{Introduction}

Retinopathy of prematurity is considered a real public health problem in low and middle-income countries like Egypt, Brazil, and India; and it is considered one of the leading causes of childhood blindness worldwide. ${ }^{1}$ Advancement in neonatal care worldwide has improved the survival rate of premature infants and meanwhile, the incidence of ROP has also increased. ${ }^{2,3}$ Few research articles evaluated the magnitude of this health problem in Egypt. There is no standard screening system in Egypt. Furthermore, we had screened babies more than 1500 g, more than 32 weeks gestational age (GA) and found signs of ROP, so, we decided to expand our inclusion criteria to include babies up to $2000 \mathrm{~g}$ of birth weight and up to 34 weeks GA in addition to older and heavier babies with unstable course in NICUs.

Many risk factors have been associated with developing ROP as low birth weight, ${ }^{4,5}$ low gestational age, sepsis, ${ }^{6}$ apnea and prolonged exposure to 
supplementary oxygen. ${ }^{7}$ In the current study, we evaluate the incidence, risk factors of ROP in the biggest NICU in Itay Elbaroud city, Behera province, Egypt.

\section{Aim of the Work}

The aim of this study was to evaluate the incidence of ROP at a big NICU in Itay Elbaroud city, Behera province, Egypt, along with the risk factors for this big public health problem.

\section{Methods}

This is a retrospective cross-sectional study in which we reviewed the charts of 240 infants who underwent fundus examination for both eyes for screening of ROP in the biggest NICU in Itay Elbaroud city, Behera province, Egypt between October 1, 2018 and October 31, 2020. The criteria of screening were infants with GA $\leq 34$ weeks, birth weight $(\mathrm{BW}) \leq 2000 \mathrm{~g}$ or infants with unstable course. Ethical Committee approval from Tanta University, Egypt was obtained. The study was conducted in accordance with the tenets of the Declaration of Helsinki and the guidelines of good clinical practice. Informed consent was signed by the parent or the legal guardian of the infant before enrollment.

Baseline characteristics of the patients, including gender, gestational age at birth, birth weight, stage of ROP at presentation, and presence of multiple pregnancies, were collected from the charts. Risk factors of ROP were evaluated including oxygen therapy during admission in NICU, apnea, sepsis, thrombocytopenia, blood transfusion, exchange transfusion and phototherapy. The main outcome measures were the incidence, severity and management of ROP. The relationship between clinical risk factors and development of ROP was analyzed.

\section{Eye Examination Method}

One retina specialist (RG) who had sufficient training and experience to diagnose and identify stages and zones of ROP performed all examinations. Pupils were dilated with $0.5 \%$ tropicamide and $0.5 \%$ phenylephrine drops two hours before examination. Indirect ophthalmoscopy was routinely used with a pediatric lid speculum and scleral indentation under topical anesthesia. Digital retinal images were also obtained using a wide-field retinal camera (RetCam II 120, Clarity Medical System Inc., Pleasanton, CA, USA) for documentation of retinal finding.

\section{Statistical Analysis}

Data was collected and stored in a spreadsheet. Descriptive continuous variables are normally distributed, therefore; they were presented using the mean and standard deviation; whereas categorical variables were reported as proportions (percent). Statistical analysis was carried out using SPSS version 23.0 (SPSS, Inc., Chicago, IL, USA) and R software (version 3.1-122; R Foundation for Statistical Computing, Vienna, Austria). For all hypothesis tests, two-sided $P$-value of $<0.05$ was considered as statistically significant.

\section{Results}

Two hundred and forty infants met our inclusion criteria of screening; among whom 132 were males (55\%), all of them are white Caucasian race. They had a mean gestational age of 33.25 \pm 2.74 weeks (range: 26-39 weeks). Mean birth weight $1955.23 \pm 692.43 \mathrm{~g}$ (range: $820-5500$ g). Eighty-two included infants (34.1\%) had ROP; including 63 infants with type 1 ROP that required therapeutic intervention. Treatment was performed in the form of intravitreal injection of an anti-VEGF drug. Ongoing surveillance for recurring ROP after anti-VEGF therapy was done by follow-up fundus examination visits even after discharging the baby from NICU until the age of 65 weeks, there was no recurring ROP after the anti-VEGF therapy.

Twenty-six multiple pregnancies were included (21 twins and 5 triplets); where 11 infants had aggressive posterior ROP, presenting with flat neovascularization at the posterior pole.

Most of the included infants in the study had stage 3 ROP (35 infants, 42.6\%) (Table 1), followed by stage 2 ROP (22 infants, 26.8\%), aggressive posterior ROP (11 infants, 13.4\%) and stage 1 ROP (10 infants, 12\%). Only one infant had stage 4 ROP $(0.01 \%)$, and none of the included infants had stage 5 ROP (Table 1).

For statistical analysis, we divided the cases per birth weight into five subgroups: less than $1000 \mathrm{~g}$ (two infants, $0.8 \%), 1000-1250 \mathrm{~g}$ (28 infants, 11.6\%), 1251-1500 g (52 infants, 21.6\%), 1501-2000 g (67 infants, 28\%) and more than $2000 \mathrm{~g}$ (91 infants, 38\%) (Table 2). And the cases are divided into three groups according gestational age (Table 3) less than 28 weeks (five infants, 2\%), 28-31 weeks (60 infants, $25 \%$ ) and more than 31 weeks (175 infants, $72.9 \%$ ). 
Table I Demographic and Clinical Data of Included Infants

\begin{tabular}{|c|c|}
\hline Number of infants & 240 \\
\hline Gender & $\begin{array}{l}\text { Male I } 32(55 \%) \\
\text { Female I08 (45\%) }\end{array}$ \\
\hline Gestational age & $\begin{array}{l}26-39 \text { weeks } \\
(33.25 \pm 2.74)\end{array}$ \\
\hline Birth weight & $\begin{array}{l}820-5500 \mathrm{~g} \\
(1955.23 \pm 692.43)\end{array}$ \\
\hline Multiple pregnancies & $\begin{array}{l}26 \text { total } \\
21 \text { twins } \\
5 \text { triplets }\end{array}$ \\
\hline Without ROP & I58 infants (65.8.1\%) \\
\hline With ROP & $\begin{array}{l}82 \text { infants (34.1\%) } \\
\text { Stage I: } 10 \\
\text { Stage 2: } 22 \\
\text { Stage 3: } 35 \\
\text { Stage 4a: I } \\
\text { Stage 5: } 0 \\
\text { APROP: II } \\
\text { Pre-plus with immature } \\
\text { vascularization: } 3\end{array}$ \\
\hline $\begin{array}{l}\text { ROP not requiring treatment } \\
\text { (mild ROP) }\end{array}$ & 19 infants (7.9\%) \\
\hline Type I ROP & 63 infants (26.3\%) \\
\hline Aggressive posterior ROP & II infants (4.6\%) \\
\hline
\end{tabular}

Abbreviations: ROP, retinopathy of prematurity; APROP, aggressive posterior retinopathy of prematurity.

As regards risk factors of ROP, there was a significant correlation between LBW ( $\leq 1500$ gm) (OR: 4.12, CI: $2.3-$ 7.3), low gestational age ( $\leq 32$ weeks) (OR: 6.8, CI: 3.7-12.3), and oxygen supplementation through either nasal cannula (OR: 3.95, CI 1.14-13.7), CPAP (OR: 18.9, CI: 5.7-62.7) or mechanical ventilation (OR: 13.6, CI: 5.6-33.1) (Table 4).

Apnea was also a significant risk factor for development of ROP changes (OR: 15.6, CI: 8-30.2), together with thrombocytopenia (OR: 2, CI: $0.6-6.5)$ and phototherapy for jaundice (OR: 2.1, CI: 1.2-3.7).
Table 3 ROP Subgroups in Relation with GA

\begin{tabular}{|l|l|l|l|l|}
\hline GA & $\begin{array}{l}\text { No } \\
\text { ROP }\end{array}$ & ROP & $\begin{array}{l}\text { Mild } \\
\text { ROP }\end{array}$ & $\begin{array}{l}\text { Type I } \\
\text { ROP }\end{array}$ \\
\hline$<28$ weeks (5) & 3 & $2(40 \%)$ & 0 & 2 \\
$28-31$ weeks (60) & 23 & $37(61.6 \%)$ & 6 & 31 \\
$\geq 32$ weeks (175) & 132 & $43(24.5 \%)$ & 13 & 30 \\
\hline
\end{tabular}

Abbreviations: GA, gestational age; ROP, retinopathy of prematurity.

Table 4 Risk Factors Evaluated for an Association with the Development of ROP

\begin{tabular}{|l|l|l|}
\hline Risk Factors & OR & $\mathbf{9 5 C l} \%$ \\
\hline Birth weight equal or less than $1500 \mathrm{~g}$ & 4.12 & $2.3-7.3$ \\
Gestational age equal or less than 32 weeks & 6.8 & $3.7-12.3$ \\
Apnea & 15.6 & $8.05-30.2$ \\
Nasal cannula & 3.95 & $1.14-13.7$ \\
CPAP & 18.9 & $5.7-62.7$ \\
Mechanical ventilation & 13.6 & $5.6-33.1$ \\
Sepsis & 1.1 & $5.6-2.17$ \\
Thrombocytopenia & 2 & $0.6-6.5$ \\
Blood transfusion & 1.15 & $0.5-2.5$ \\
Exchange transfusion & 0.9 & $0.08-10.9$ \\
Phototherapy & 2.1 & $1.2-3.7$ \\
\hline
\end{tabular}

Abbreviations: $\mathrm{OR}$, odds ratio; $\mathrm{Cl}$, confidence interval.

\section{Discussion}

Retinopathy of prematurity is one of the leading causes of childhood blindness worldwide. Few published research articles demonstrate the magnitude of ROP as a real health-care problem in Africa and the Middle East, particularly in Egypt. The incidence of ROP in our study was $34 \%$, and the incidence of type 1 ROP which required treatment was $26.3 \%$. Treatment was performed successfully in the form of intravitreal injection of antivascular endothelial growth factor (anti-VEGF).

Our results coincide with the results of Bassiouny ${ }^{8}$ who reported an incidence of 34\% for ROP in Oman, and Maheshwari et al $^{9}$ who also reported an incidence of $27 \%$ in India. In 2008, Binkhathlan et $\mathrm{al}^{10}$ reported an

Table 2 ROP Subgroups in Relation with BW

\begin{tabular}{|l|l|l|l|l|}
\hline BW & No ROP & ROP & Mild ROP & Type I ROP \\
\hline$<1000 \mathrm{~g}(\mathrm{n}=2)$ & $\mathrm{I}$ & $\mathrm{I}(50 \%)$ & 0 & $\mathrm{I}$ \\
$1000-1250 \mathrm{~g}(\mathrm{n}=28)$ & 12 & $16(57 \%)$ & 2 & 14 \\
$1251-1500 \mathrm{~g}(\mathrm{n}=52)$ & 24 & $28(53.8 \%)$ & 3 & 25 \\
$1501-2000 \mathrm{~g}(\mathrm{n}=67)$ & $4 \mathrm{I}$ & $26(38.8 \%)$ & 7 & 19 \\
$>2000 \mathrm{~g}(\mathrm{n}=91)$ & 80 & $11(12 \%)$ & 7 & 4 \\
\hline
\end{tabular}

Abbreviations: BW, birth weight; ROP, retinopathy of prematurity. 
incidence of $56 \%$ for ROP in Saudi Arabia, while AlAmro et $\mathrm{al}^{11}$ reported an incidence of $37.4 \%$ in the neonatal intensive care unit at King Khalid University Hospital in Riyadh in 2003.

The mean gestational age for babies in our study was $33.25 \pm 2.74$ weeks, which is higher than that in other studies. Goble et $\mathrm{al}^{12}$ reported a mean gestational age of $29.1 \pm 2.1$ weeks, while Shah et $\mathrm{al}^{13}$ reported a mean gestational age of $29.7 \pm 2.2$ weeks, which may indicate a higher rate of mortality among infants with lower gestational age in our country.

Gestational age equal or less than 32 weeks was a risk factor for development of ROP (OR: 6.8). We found that $57 \%$ of babies born before 32 weeks developed ROP, while only $17 \%$ of babies born after 32 weeks developed ROP.

The mean birth weight for babies in our study was $1955.23 \pm 692.43 \mathrm{~g}$. Thirty-nine percent of babies between 1500 and $2000 \mathrm{~g}$ developed ROP; so every baby with birth weight less than $2000 \mathrm{~g}$ should be routinely examined by a trained ophthalmologist to exclude ROP. This is contrary to Hadi and Hamdy ${ }^{14}$ who recommended to keep the upper limit of screening of babies for ROP at $1500 \mathrm{~g}$.

In our study, birth weight $\leq 1500 \mathrm{~g}$ was a risk factor for development of ROP (OR: 4). Fifty-five percent of these babies developed ROP, while only $38.8 \%$ of babies with birth weight between 1500 and $2000 \mathrm{~g}$ developed ROP.

We evaluated the role of apnea, oxygen supplementations (nasal cannula, CPAP, mechanical ventilation) sepsis, thrombocytopenia, blood transfusion, exchange transfusion, and phototherapy as possible risk factors for development of ROP. There was a positive correlation between oxygen supplementation either with nasal cannula (OR: 3.95, CI: 1.14-13.7), CPAP (OR: 18.9, CI: 5.7-62.7) or mechanical ventilation (OR: 13.6, CI: 5.6-33.1) and development of ROP. Our results are in agreement with other studies which confirmed the association between the risk of ROP and the use of mechanical ventilation ${ }^{15}$ and CPAP. ${ }^{13}$

The occurrence of thrombocytopenia (OR: 2, CI: 0.6$6.5)^{16}$ is another significant risk factor for development of ROP, in addition to neonatal apnea (OR: 15.6, CI: 8-30.2) and phototherapy for jaundice (OR: 2.1, CI: 1.2-3.7). ${ }^{17}$

\section{Conclusion}

ROP is a real public health problem in Egypt. Immaturity, low birth weight, low gestational age, oxygen administration, apnea, thrombocytopenia, and jaundice are important risk factors for development of ROP. Wise use of oxygen and a strict screening program that require cooperation between neonatal specialists and trained ophthalmology subspecialist are highly encouraged to avoid the devastating complications of this serious condition that has a high incidence among neonates in Egypt.

\section{Disclosure}

The authors report no conflicts of interest in this work.

\section{References}

1. Nuddleman E, Kilic I, Gaber R, et al. Glaucona after lens sparing vitrectomy for advanced retinopathy of prematurity. Ophthalmology. 2018;125(5):671-675. doi:10.1016/j.ophtha.2017.11.009

2. Valentine PH, Jackson JC, Kalina RE, et al. Increased survival of low birth weight infants: impact on the incidence of retinopathy of prematurity. Pediatrics. 1989;84:442-445.

3. Gibson DL, Sheps SB, Uh SH, et al. Retinopathy of prematurity-induced blindness: birth weight-specifc survival and the new epidemic. Pediatrics. 1990;6:405-412.

4. Darlow BA, Hutchinson JL, Henderson-Smart DJ, et al. Prenatal risk factors for severe retinopathy of prematurity among very preterm infants of the Australian and New Zealand neonatal network. Pediatrics. 2005;115(4):990-6. doi:10.1542/peds.2004-1309

5. Dhaliwal CA, Fleck BW, Wright E, et al. Retinopathy of prematurity in small-for-gestational age infants compared with those of appropriate size for gestational age. Arch Dis Child Fetal Neonatal Ed. 2009;94:F193-5.

6. Gupta VP, Dhaliwal U, Sharma R, Gupta P, Rohatgi J. Retinopathy of prematurity - risk factors. Indian J Pediatr. 2004;71(10):887-92. doi:10.1007/BF02830827

7. Kim TI, Sohn J, Pi SY, et al. Postnatal risk factors of retinopathy of prematurity. Paediatr Perinat Epidemiol. 2004;18(2):130-4. doi:10.1111/j.1365-3016.2003.00545.x

8. Bassiouny MR. Risk factors associated with retinopathy of prematurity: a study from Oman. $J$ Trop Pediatr. 1996;42(6):355-358. doi:10.1093/tropej/42.6.355

9. Maheshwari R, Kumar H, Paul VK, Singh M, Deorari AK, Tiwari HK. Incidence of retinopathy of prematurity in a tertiary care newborn unit in New Delhi. Natl Med J India. 1996;9:211-214.

10. Binkhathlan AA, Almahmoud LA, Saleh MJ, Srungeri S. Retinopathy of prematurity in Saudi Arabia: incidence, risk factors, and the applicability of current screening criteria. Br J Ophthalmol. 2008;92(2):167-169. doi:10.1136/bjo.2007.126508

11. Al-Amro SA, Al-Kharf TM, Thabit AA, Al-Mofada SM. Retinopathy of prematurity at a university hospital in Riyadh, Saudi Arabia. Saudi Med J. 2003;24:720-784.

12. Goble RR, Jones HS, Fielder AR. Are we screening too many babies for retinopathy? Eye. 1997;11(4):509-514. doi:10.1038/eye.1997.136

13. Shah VA, Yeo CL, Ling YL, Ho LY. Incidence, risk factors of retinopathy of prematurity among very low birth weight infants in Singapore. Ann Acad Med Singapore. 2005;34:169-178.

14. Hadi AMA, Hamdy S. Correlation between risk factors during neonatal period and appearance of retinopathy of prematurity in preterm infants in neonatal intensive care units in Alexandria, Egypt. Clin Ophthalmol. 2013;7:831-837. doi:10.2147/OPTH.S40136

15. Al-Amro SA, Al-Khar TM, Thabit AA, Al-Mofada SM. Risk factors for acute retinopathy of prematurity. Compr Ther. 2007;33(2):73-77. doi:10.1007/s12019-007-8008-5

16. Jensen AK, Ying GS, Huang J, et al. Thrombocytopenia and retinopathy of prematurity. $J$ AAPOS. 2011;15(1):e3-e4.

17. Ali YF, El-Morshedy S, Imam AA, et al. The role of serum apelin in retinopathy of prematurity. Clin Ophthalmol. 2017;11:387-392. doi:10.2147/OPTH.S127943 


\section{Publish your work in this journal}

Clinical Ophthalmology is an international, peer-reviewed journal covering all subspecialties within ophthalmology. Key topics include: Optometry; Visual science; Pharmacology and drug therapy in eye diseases; Basic Sciences; Primary and Secondary eye care; Patient Safety and Quality of Care Improvements. This journal is indexed on PubMed

Submit your manuscript here: https://www.dovepress.com/clinical-ophthalmology-journal
Central and CAS, and is the official journal of The Society of Clinical Ophthalmology (SCO). The manuscript management system is completely online and includes a very quick and fair peer-review system, which is all easy to use. Visit http://www.dovepress.com/ testimonials.php to read real quotes from published authors. 